\title{
REVIEW
}

\section{OCCURRENCE OF HOSPITAL-ACQUIRED INFECTIONS IN RELATION TO MISSED NURSING CARE: A LITERATURE REVIEW}

\author{
Eva Mynař́ková1, Darja Jarošová ${ }^{2}$, Eva Janíková ${ }^{1,2}$, Ilona Plevová², Andrea Polanská1, Renáta \\ Zeleníková ${ }^{2}$
}

${ }^{1}$ Department of Nursing Care, University Hospital in Ostrava, Czech Republic

${ }^{2}$ Department of Nursing and Midwifery, Faculty of Medicine, University of Ostrava, Czech Republic

Received October 1, 2019; Accepted January 7, 2020. Copyright: This is an open access article under the CC BY-NC-ND license.

\begin{abstract}
Aim: To find an association between missed nursing care and hospital-acquired infections or other adverse events. Design: A literature review. Methods: The literature review included full texts of articles published in English in 2009-2018 and obtained by searching the following bibliographic databases: PubMed, Bibliographia Medica Čechoslovaca and ProQuest Central. Twenty-six articles were assessed for eligibility, of which nine articles meeting all the criteria were analyzed in detail. Results: The analyzed studies have confirmed that missed nursing care is associated with hospital-acquired infections, with bloodstream infections, urinary tract infections and pneumonia being most frequent. Apart from hospital-acquired infections and missed nursing care, other adverse events were reported such as pressure ulcers, patient falls and medication error; moreover, patient dissatisfaction rose. Lower levels of missed nursing care were associated with a lower incidence of hospital-acquired infections and other adverse events. Conclusion: Tackling the issue of missed nursing care would contribute to a lower incidence of hospital-acquired infections that harm patient health, prolong hospital stays and considerably increase healthcare costs.
\end{abstract}

Keywords: adverse events, hospital-acquired infections, missed nursing care.

\section{Introduction}

Hospital-acquired infections (HAIs) always complicate the patients' hospital stay and, at least temporarily, impair their quality of life. However, infections may also cause permanent health damage with serious consequences, even leading to disability (Jindrák et al., 2014). In the US alone, HAIs affect $5-10 \%$ of patients admitted to hospitals, that is, nearly 2 million people a year. Of those, approximately 100,000 individuals die due to HAIs (The Research Committee of the Society of Healthcare Epidemiology of America, 2010). In Europe, a HAI is contracted by one out of eighteen hospitalized patients. Patients most at risk for HAIs are those in intensive care units (Suetens et al., 2013). A survey of the prevalence and epidemiological characteristics of HAIs in Europe showed that the most frequently reported types were respiratory tract infections (pneumonia 19.4\%, lower respiratory tract infections $4.1 \%$ ), surgical site infections $(19.6 \%)$, urinary tract infections $(19.0 \%)$, bloodstream infections (10.1\%) and gastrointestinal infections (7.7\%) (Suetens et al., 2013). In the Czech Republic, no large prevalence studies providing representative results have been conducted; thus, only

Corresponding author: Eva Mynařiková, Department of Nursing Care, University Hospital in Ostrava, 17. listopadu 1790/5, Ostrava-Poruba, Czech Republic; email: eva.mynarikova@fno.cz qualified estimates may be made. It is estimated that annually approximately 100,000 cases of HAIs of various types and severity occur in the country. As a direct result, as many as 3000 patients may die each year (Jindrák et al., 2014).

An important factor affecting the development of HAIs is nursing care quality (Boev \& Kiss, 2017; Quinn et al., 2014). The last decade has witnessed the phenomenon of missed nursing care (Kalánková et al., 2019; Kalisch 2006; Kalisch et al., 2009a, 2009b; Kalisch \& Lee, 2010; Schubert et al., 2007; Schubert et al., 2009). The term refers to nursing care required by patients that is omitted, either in part or whole, or delayed. It is often seen as a lack-of-time issue that triggers a process of implicit rationing through clinical priorities set by nurses and nursing staff (Hessels et al., 2015; Kalisch 2006; Kalisch et al., 2009a, 2009b; Schubert et al., 2007). Numerous studies point to the fact that missed nursing care is seen throughout hospitals, with no exceptions (Ausserhofer et al., 2014; Kalisch et al., 2009a, 2009b; Kalisch et al., 2011a, 2011b; Kalisch et al., 2012; Kalisch \& Lee 2010; Schubert et al., 2013; Zeleníková et al., 2019). The main reasons for missed nursing care are labor resources, material resources, communication and work environment. It has been shown that the higher staffing level and the associated higher teamwork 
level, the less prevalent missed nursing care (Kalisch \& Xie, 2014; Lee \& Scott, 2018).

The consequences of missed nursing care are a higher risk for adverse patient events, leading to increased healthcare costs. Studies on the association between missed nursing care and patient outcomes confirmed its negative impact on a range of clinical outcomes including patient dissatisfaction and, eventually, increased mortality (Ambrosi et al., 2017; Carthon et al., 2015; Griffiths et al., 2018; Lucero et al., 2010; Schubert et al., 2012). Investigations into the effect of missed nursing care on the quality of patient care showed that unmet patient needs increased the incidence of nosocomial infections, falls with injury, pressure ulcers, medication errors and also considerably influenced patient satisfaction (Ausserhofer et al., 2013; Lucero et al., 2010; Papastavrou et al., 2014; Schubert et al., 2009). Three types of adverse events (nosocomial infections, pressure ulcers and patient dissatisfaction) are observed even when the level of missed nursing care is low, suggesting that missed nursing care is a major threat to patient safety and healthcare quality (Schubert et al., 2009).

\section{Aim}

The literature review aimed to find an association between missed nursing care and HAIs or other adverse events.

\section{Methods}

\section{Design}

A literature review.

\section{Eligibility criteria}

The literature review included full texts of peer reviewed articles published in English in 2009-2018. The articles eligible for inclusion were those containing concepts concerning missed nursing care and reports on the incidence of nosocomial infections / HAIs in adult patients.

The relevant sources concerning the issue were obtained using the following bibliographic databases: PubMed, Bibliographia Medica Čechoslovaca and ProQuest Central.

\section{Search Strategy}

The search was conducted using the following keywords: omitted nursing care, missed nursing care, unfinished nursing care, nosocomial infections and hospital-acquired infections. To combine the keywords in the search, the Boolean operators AND and $\mathrm{OR}$ were used. The literature sources were searched between November 2018 and June 2019.

\section{Study Selection inc. PRISMA flow diagram}

The studies were selected and classified in accordance with the recommended PRISMA flow diagram (Moher et al., 2009) (Figure 1). A total of 2,400 records were identified. After exclusion of irrelevant studies, 640 records were included in the review process and their abstracts were analyzed. The analysis of abstracts found that 614 records were not relevant to the topic and those were subsequently excluded. Twenty-six full-text articles were assessed for eligibility; of those, 17 were excluded as instead of missed nursing care, they were only concerned with some of its factors, in particular nurse understaffing, inadequate staff education and inadequate nursing care related to nosocomial infections. Eventually, nine articles meeting all the criteria were included in the literature review.

\section{Evaluation of quality of articles}

Quality assessments were performed separately by two reviewers (EM, DJ), and disagreements were discussed. The methodological quality of selected studies were assessed with the critical appraisal tools of the JBI. Disagreement regarding quality of studies fortheir inclusion was resolved by discussion between the researchers (EM, DJ, AP).

\section{Data extraction}

The articles that were selected for full-text review and analysis were mapped to identify the most relevant relevant categories. Three authors performed data extraction using a data extraction sheet. This list contained information on authors, country of origin, research design, study objectives, forms of data processing, research outcomes and conclusions. After completing the mapping process, we synthesized the results for summary findings related to the observed variables.

\section{Results}

The records included in the review report an association between missed nursing care and HAIs (Table 1). The studies have confirmed that missed nursing care results in increased incidence of bloodstream infections, urinary tract infections, pneumonia and other adverse events.

Higher levels of rationing of nursing care / omitted nursing care led to an increase in HAIs (Ausserhofer et al., 2013) including urinary tract infections (25.5\%), bloodstream infections (16.2\%) and pneumonia (10.9\%). Apart from infections, the authors also identified other adverse events associated with nursing care such as medication errors (10.9\%), patient falls $(9.6 \%)$ and pressure ulcers (5\%). Moreover, patient dissatisfaction rose (Ausserhofer et al., 2013). Missed 


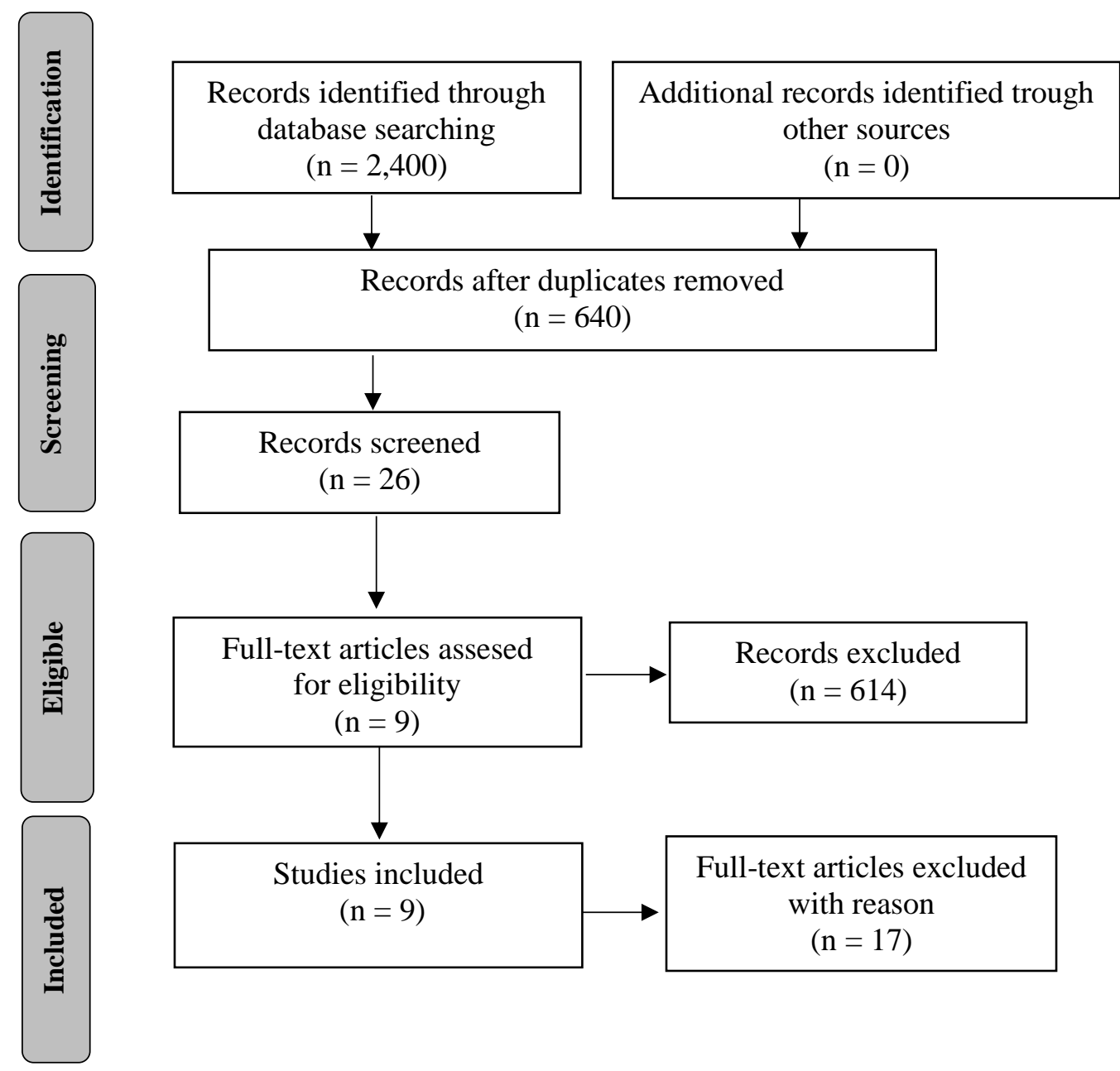

Figure 1 Flow diagram for the process of systematic classification and assessment of the relevance and quality of studies on HAIs associated with missed/omitted nursing care.

nursing care contributes to the development of urinary tract infections, pneumonia, pressure ulcers and delirium, particularly in elderly patients who are at a higher risk for complications (Bail \& Grealish, 2016).

A study by Kalisch et al. (2014) aimed to determine the extent and type of patient-reported missed nursing care and its association with adverse events as reported by patients. There were more elements of missed nursing care in the domain of basic care (mouth care, helping with ambulation, getting into a chair, helping with bathing). The most frequent patient-reported adverse events were pressure ulcers, new infections, falls and medication errors. Missed nursing care had a considerable impact on the occurrence of adverse events in patients (Lucero et al., 2010). An increase in one unmet nursing care need on average increased the relative proportion of nosocomial infections $(31 \%)$, patient falls with injury $(20 \%)$ and medication errors (15\%) (Lucero et al., 2010). A cross-sectional study by Nelson \& Flynn (2015) showed that 7 out of 12 nurse-reported categories of missed care activities were significantly correlated with the incidence of urinary tract infections, with $40 \%$ of these infections being explained by failure to administer medications on time or to provide adequate patient surveillance. The association between rationing of nursing care and adverse events (nosocomial infections, pressure ulcers, medication errors, falls with injury and patient dissatisfaction) was also described in a systematic review by Papastavrou et al. (2014). The most common elements of rationed care were patient ambulation, feeding, education, discharge planning, communication and psychological and emotional support. Ralph \& Viljoen (2018) pointed to missed nursing care and its implications for patients, in particular an increased incidence of HAIs (bloodstream infections, pneumonia, urinary tract infections). In addition to the increase in HAIs, missed nursing care is also associated with other adverse events such as medication errors, patient falls or pressure ulcers. Similarly, a systematic review of the impact of missed nursing care on outcomes of patients 
Table 1 Occurrence of HAIs and other adverse events in relation to missed/omitted/unfinished nursing care

\begin{tabular}{lll}
\hline Authors (year) & Design & Objective \\
\hline $\begin{array}{l}\text { Ausserhofer } \\
\text { et al. (2013) }\end{array}$ & Cross-sectional study & $\begin{array}{l}\text { To explore the relationship } \\
\text { between patient safety climate } \\
\text { and patient outcomes in Swiss } \\
\text { acute care hospitals. }\end{array}$
\end{tabular}

Bail \& Grealish Narrative literature To assess the relationship (2016) analysis between rationing of nursing care and hospital-acquired complications in older patients.

Kalisch et al. Cross-sectional (2014) descriptive study

To determine the extent and type of missed nursing care and the association with patientreported adverse events.

Lucero et al. Secondary analysis (2010) of cross-sectional data

Nelson \& Flynn Cross-sectional study (2015)

Papastavrou et Systematic review al. (2014) of quantitative studies

\section{Ralph \& Viljoen Editorial} (2018)

Recio-Saucedo et al. (2018)

Systematic review of the literature
To examine the association between unmet nursing care needs and the occurrence of adverse events.

To determine the frequencies and types of missed nursing care in nursing homes and the relationship between missed care and the incidence of urinary tract infections.

To identify the factors related to nursing care rationing and its impact on nurse and patient outcomes.

To point to the impact of missed nursing care on patient safety.

Systematic review of the impact of the impact of missed nursing care on outcomes in adults in acute care hospitals.

\section{Main findings}

Patient safety climate was not a predictor of for adverse events. Implicit rationing of nursing care resulted in significant decrease in the odds of patient satisfaction and significant increase in the odds of medication errors, bloodstream infections and pneumonia.

The analysis confirmed the relationship between rationed nursing care and urinary tract infections, pneumonia, pressure ulcers and delirium.

The most frequently reported elements of missed nursing care were mouth care, ambulation, providing information or education and bathing. The most common patient-reported adverse events were pressure ulcers, medication errors and new infections.

There was an association between unmet nursing care needs and adverse events, in particular nosocomial infections, falls and medication errors.

The most frequent types of missed nursing care associated with the incidence of urinary tract infections were medication errors and inadequate patient surveillance.

The most common causes of nursing care rationing were nurse-patient workload and communication barriers. The most frequent elements of rationed care were communication with patients and mouth care. The most frequent adverse events were patient falls, nosocomial infections, pressure ulcers, medication errors and low patient satisfaction levels.

There is an association between missed nursing care and falls, pressure ulcers, bloodstream infections, pneumonia, urinary tract infections and medication errors.

Seven studies reported associations between missed nursing care and urinary tract infections, bloodstream infections, pneumonia, patient falls, pressure ulcers and medication errors. Fours studies found significantly decreased patient satisfaction. Three studies failed to show an association between missed nursing care and mortality.

Rationing of nursing care considerably influenced nosocomial infections, pressure ulcers and patient satisfaction.
Schubert
et al.

(2009)
Descriptive crosssectional multicenter study
To describe the levels of rationing of nursing care. To identify thresholds of the influence of rationing on nurses and patients. 
staying on acute hospital wards confirmed higher rates of adverse events, in particular bloodstream infections, pneumonia, urinary tract infections, medication errors, patient falls and pressure ulcers (Recio-Saucedo et al., 2018). One of the first studies on the impact of rationing of nursing care on patient outcomes showed that nosocomial infections were the most common adverse events alongside pressure ulcers and patient dissatisfaction (Schubert et al., 2009).

\section{Discussion}

Based on results of large prevalence studies, it is estimated that approximately one in twenty patients admitted to hospital develops at least one HAI of varied severity (Jindrák et al., 2014). Documents accompanying the Council Recommendation of 9 June 2009 on patient safety, including the prevention and control of healthcare associated infections state that each year approximately 37,000 patients die as a direct consequence and 111,000 patients as an indirect consequence of HAIs acquired in European acute care hospitals (Suetens et al., 2013). HAIs do not pose only a local threat to patients at risk but are a complex problem affecting the entire healthcare system (Jindrák et al., 2014).

Many authors (Ausserhofer et al., 2013; Bail \& Grealish, 2016; Kalisch et al., 2014; Lucero et al., 2010; Nelson \& Flynn, 2015; Papastavrou et al., 2014; Ralf \& Viljoen, 2018; Recio-Saucedo et al., 2018; Schubert et al., 2009) point to the fact that nursing care is greatly associated with HAIs. Missed nursing care, in particular mouth care, increases the incidence of nonventilator hospital-acquired pneumonia and thus healthcare costs in pneumonia patients (Quinn et al., 2014; Tesoro et al., 2018).

Adverse events (nosocomial infections, medication errors, pressure ulcers and patient falls) are contributed to by nurses' lack of time to perform necessary nursing care activities (Lucero et al., 2010). One of the main causes of adverse events is excessive nursing workload, that is, rotating shifts, nurse understaffing and working overtime (Abadi et al., 2017; Boev \& Kiss 2017; Halain et al., 2018; Oliveira et al., 2016; Schwab et al., 2012). Stress is put on the need for comprehensive workforce planning to optimize nursing care provided to patients. The existence of missed nursing care is also influenced by the qualification structure of nursing teams in which, due to financial reasons, experienced registered nurses are replaced by less trained and less experienced nurses (Palese et al., 2015). The incidence of HAIs and other adverse events is also influenced by nurse-physician collaboration (Boev \& Xia, 2015; Kang et al., 2014). Lee \& Scott (2018) suggested an association between nurses' work environment and HAIs (bloodstream infections, ventilator-associated pneumonia, catheter-associated sepsis) as well as other adverse events (pressure ulcers, patient falls, medication errors, patient dissatisfaction).

As a result of missed nursing care, the quality of care and patient safety are compromised (Bail \& Grealish, 2016; Boev \& Kiss, 2017). Research results (Ausserhofer et al., 2014; Bail \& Grealish, 2016; Lucero et al., 2010; Papastavrou et al., 2014; RecioSaucedo et al., 2018) have shown that missed nursing care is an international problem. Identification of missed nursing care and its causes should result in the restructuring of nursing care services aiming to tackle the issue of missed nursing care and thus to improve the quality and safety of patient care (Kalisch et al., 2009b). The causes and consequences of missed nursing care are similar across hospitals, with labor resources being most frequent, followed by material resources and communication. These findings suggest that strategies focused on improving teamwork and collaboration, excessive workload, poor personal deployment and flows in patient acuity and volume may create the conditions minimizing the likelihood of missed nursing care (Kalisch et al., 2011a).

Missed nursing care is an increasingly important phenomenon in healthcare, affecting the quality of care, increasing the incidence of infections, prolonging hospital stays and patient recovery and thus increasing care costs. The provision of safe care prevents patients from harm and requires a good system for preventing hospital errors. The goal is to build a culture of safe care involving all health professionals, health organizations and patients themselves (Wakefield, 2014). Poor patient safety represents a serious problem in healthcare facilities as well as a considerable financial burden. A sizable proportion of adverse events may be prevented, with most of them appearing to be systemic factors (Council recommendation..., 2009). According to the recommendation, a strategy for the prevention and control of HAIs should be implemented with the following goals: to implement prevention and control measures at both national and regional levels as well as infection prevention and control measures in healthcare settings, to establish active surveillance systems, to foster education and training of healthcare workers and to facilitate the patients' access to information.

\section{Conclusion}

There is evidence that missed nursing care is associated with hospital-acquired infections. The provision of high-quality nursing care may reduce 
the incidence of HAIs that pose a threat to patient safety, prolong hospital stays and considerably increase healthcare costs. Healthcare facility administrators should make efforts to optimize nursing care and reduce missed care.

\section{Ethical aspects and conflict of interest}

The authors state that they are not aware of any conflict of interests regarding this paper.

\section{Acknowledgements}

Supported by Ministry of Health of the Czech Republic, grant nr. NV18-09-00420. All rights reserved.

\section{Author contributions}

Concept and design (EM, DJ, RZ), analysis and data interpretation (EM, DJ, AP), preparation of the manuscript (EM, DJ), manuscript critical revision (EJ, IP, AP), final revision (EM, DJ, IP).

\section{References}

Abadi, M. B. H., Akbari, H., Akbari, H., Gholami-Fesharaki, M., \& Ghasemi, M. (2017). The association of nursing workloads, organizational, and individual factors with adverse patient outcome. Iranian Red Crescent Medical Journal, 19(4):e43444. https://doi.org/10.5812/ircmj.43444

Ambrosi, E., De Togni, S., Guarnier, A., Barelli, P., Zambiasi, P., Allegrini, E., Bazoli, L., Casson, P., Marin, M., Padovan, M., Picogna, M., Taddia, P., Salmaso, D., Chiari, P., Frison, T., Marognolli, O., Canzan, F., Saiani, L., \& Palese, A. (2017). In-hospital elderly mortality and associated factors in 12 Italian acute medical units: findings from an exploratory longitudinal study. Aging Clinical and Experimental Research, 29(3):517-527. https://doi.org/10.1007/s40520016-0576-8

Ausserhofer, D., Schubert, M., Desmedt, M., Blegen, M. A., De Geest, S., \& Schwendimann, R. (2013). The association of patient safety climate and nurse-related organizational factors with selected patient outcomes: a cross-sectional survey. International Journal of Nursing Studies, 50(2):240252. https://doi.org/10.1016/j.ijnurstu.2012.04.007

Ausserhofer, D., Zande, B., Busse, R., Schubert, M., De Geest, S., Rafferty, A. M., Ball, J., Scott, A., Kinnunen, J., Heinen, M., Strømseng Sjetne, I., Moreno-Casbas, T., Kózka, M., Lindqvist, R., Diomidous, M., Bruyneel, L., Sermeus, W., Aiken, L., Schwendimann, R., \& RN4CAST consortium. (2014). Prevalence, patterns and predictors of nursing care left undone in European hospitals: results from the multicountry cross-sectional RN4CAST study. BMJ Quality and Safety, 23(2):126-135. https://doi.org/10.1136/bmjqs2013-002318

Bail, K., \& Grealish, L. (2016). 'Failure to maintain': a theoretical proposition for a new quality indicator of nurse care rationing for complex older people in hospital. International Journal of Nursing Studies, 63:146-161. https://doi.org/10.1016/j.ijnurstu.2016.08.001
Boev, C., \& Kiss, E. (2017). Hospital-acquired infections: current trends and prevention. Critical Care Nursing Clinics of North America, 29(1):51-65.

https://doi.org/10.1016/j.cnc.2016.09.012

Boev, C., \& Xia, Y. (2015). Nurse-physician collaboration and hospital-acquired infections in critical care. Critical Care Nurse, 35(2):66-72. https://doi.org/10.4037/ccn2015809

Carthon, J. M., Lasater, K. B., Sloane, D. M., \& Kutney-Lee, A. (2015). The quality of hospital work environments and missed nursing care is linked to heart failure readmissions: a cross-sectional study of US hospitals. BMJ Quality and Safety, 24(4):255-263. https://doi.org/10.1136/bmjqs-2014$\underline{003346}$

Council of the European Union. (2009) Council Recommendation of 9 June 2009 on patient safety, including the prevention and control of healthcare associated infections. European Council.

https://www.consilium.europa.eu/en/council-eu/

Griffiths, P., Recio-Saucedo, A., Dall'Ora, C., Briggs, J., Maruotti, A., Meredith, P., Smith, G. B., Ball, J., \& Missed Care Study Group. (2018). The association between nurse staffing and omissions in nursing care: a systematic review. Journal of Advanced Nursing, 74(7):1474-1487. https://doi.org/10.1111/jan.13564

Halain, A. A., Soh, K. L., Ibrahim, A., Japar, S., Ong, S. L., Sani, A. M., \& Soh, K. G. (2018). Nursing workload in relation to nosocomial infection in public hospital intensive care unit, Malaysia. Research Journal of Pharmacy and Technology, 11(9):3892-3896.

https://doi.org/10.5958/0974-360X.2018.00713.8

Hessels, A. J., Flynn, L., Cimiotti, J. P., Cadmus, E., \& Gershon, R. R. (2015). The impact of the nursing practice environment on missed nursing care. Clinical Nursing Studies, 3(4):60-65. https://doi.org/10.5430/cns.v3n4p60

Jindrák, V., Hedlová, D., Urbášková, P., \& kolektiv. (2014). Antibiotická politika a prevence infekcí v nemocnici. Mladá fronta. (in Czech)

Kalánková, D., Žiaková, K., \& Kurucová, R. (2019). Approaches to understanding the phenomenon of $\mathrm{missed} / \mathrm{rationed} / \mathrm{unfinished} \mathrm{care} \mathrm{-} \mathrm{a} \mathrm{literature} \mathrm{review.} \mathrm{Central}$ European Journal of Nursing and Midwifery, 10(1):10051016. http://dx.doi.org/10.15452/CEJNM.2019.10.0007

Kalisch, B. J. (2006). Missed nursing care: a qualitative study. Journal of Nursing Care Quality, 21(4):306-313. https://doi.org/10.1097/00001786-200610000-00006

Kalisch, B. J., Landstrom, G. L., \& Hinshaw, A. S. (2009a). Missed nursing care: a concept analysis. Journal of Advanced Nursing, 65(7):1509-1517. https://doi.org/10.1111/j.13652648.2009.05027.x

Kalisch, B. J., Landstrom, G., \& Williams, R. A. (2009b). Missed nursing care: errors of omission. Nursing Outlook, 57(1):3-9. https://doi.org/10.1016/j.outlook.2008.05.007

Kalisch, B. J., \& Lee, K. H. (2010). The impact of teamwork on missed nursing care. Nursing Outlook, 58(5):233-241. https://doi.org/10.1016/j.outlook.2010.06.004

Kalisch, B. J., Tschannen, D., \& Lee, K. H. (2011a). Do staffing levels predict missed nursing care? International Journal for Quality in Health Care, 23(3):302-308. https://doi.org/10.1093/intqhc/mzr009

Kalisch, B. J., Tschannen, D., Lee, H., \& Friese, C. R. (2011b). Hospital variation in missed nursing care. American Journal of Medical Quality, 26(4):291-299. https://doi.org/10.1177/1062860610395929 
Kalisch, B. J., Gosselin, K., \& Choi, S. H. (2012). A comparison of patient care units with high versus low levels of missed nursing care. Health Care Management Review, 37(4):320-328.

https://doi.org/10.1097/HMR.0b013e318249727e

Kalisch, B. J., \& Xie, B. (2014). Errors of omission: missed nursing care. Western Journal of Nursing. Research, 36(7):875-890.

https://doi.org/10.1016/j.outlook.2008.05.007

Kalisch, B. J., Xie, B., \& Dabney, B. W. (2014). Patientreported missed nursing care correlated with adverse events. American Journal of Medical Quality, 29(5):415-422. https://doi.org/10.1177/1062860613501715

Kang, J. H., Kim, C. W., \& Lee, S. Y. (2014). Nurse-perceived patient adverse events and nursing practice environment. Journal of Preventive Medicine \& Public Health, 47(5):273280. https://doi.org/10.3961/jpmph.14.019

Lee, S. E., \& Scott, L. D. (2018). Hospital nurses' work environment characteristics and patient safety outcomes: a literature review. Western Journal of Nursing Research, 40(1):121-145. https://doi.org/10.1177/0193945916666071

Lucero, R. J., Lake, E. T., \& Aiken, L. H. (2010). Nursing care quality and adverse events in US hospitals. Journal of Clinical Nursing, 19(15-16):2185-2195. https://doi.org/10.1111/j.1365-2702.2010.03250.x

Moher, D., Liberati, A., Tetzlaff, J., \& Altman, D. G. (2009). PRISMA Group. Preferred reporting items for systematic reviews and meta-analyses: the PRISMA statement. Annals of Internal Medicine, 151(4):264-269.

https://doi.org/10.7326/0003-4819-151-4-200908180-00135

Nelson, S. T., \& Flynn, L. (2015). Relationship between missed care and urinary tract infections in nursing homes. Geriatric Nursing, 36(2):126-130.

https://doi.org/10.1016/j.gerinurse.2014.12.009

Oliveira, A. C., Garcia, P. C., \& Nogueira, L. S. (2016). Nursing workload and occurrence of adverse events in intensive care: a systematic review. Revista Da Escola De Enfermagem USP, 50(4): 683-694.

http://dx.doi.org/10.1590/S0080-623420160000500020

Palese, A., Ambrosi, E., Prosperi, L., Guarnier, A., Barelli, P., Zambiasi, P., Allegrini, E., Bazoli, L., Casson, P., Marin, M., Padovan, M., Picogna, M., Taddia, P., Salmaso, D., Chiari, P., Marognolli, O., Canzan, F., Gonella, S., \& Saiani, L. (2015). Missed nursing care and predicting factors in the Italian medical care setting. Internal and Emergency Medicine, 10(6):693-702. https://doi.org/10.1007/s11739$\underline{015-1232-6}$

Papastavrou, E., Andreou, P., \& Efstathiou, G. (2014). Rationing of nursing care and nurse-patient outcomes: a systematic review of quantitative studies. The International Journal of Health Planning and Management, 29(1):3-25. https://doi.org/10.1002/hpm.2160

Quinn, B., Baker, D. L., Cohen, S., Stewart, J. L., Lima, C. A., \& Parise, C. (2014). Basic nursing care to prevent nonventilator hospital-acquired pneumonia. Journal of Nursing Scholarship, 46(1):11-19.

https://doi.org/10.1111/jnu.12050

Ralph, N., \& Viljoen, B. (2018). Fundamentals of missed care: implications for the perioperative environment (Editorial). Journal of Perioperative Nursing, 31(3):3-4. https://doi.org/10.26550/2209-1092.1038
Recio-Saucedo, A., Dall'Ora, C., Maruotti, A., Ball, J., Briggs, J., Meredith, P., Redfern, O. C., Kovacs, C., Prytherch, D., Smith, G. B., \& Griffiths, P. (2018). What impact does nursing care left undone have on patient outcomes? Review of the literature. Journal of Clinical Nursing, 27(1112):2248-2259. https://doi.org/10.1111/jocn.14058

Schubert, M., Glass, T. R., Clarke, S. P., Schaffert-Witvliet, B., $\&$ De Geest, S. (2007). Validation of the Basel extent of rationing of nursing care instrument. Nursing Research, 56(6):416-424.

https://doi.org/10.1097/01.NNR.0000299853.52429.62

Schubert, M., Clarke, S., Glass, T. R., Schaffert-Witvliet, B., \& De Geest, S. (2009). Identifying thresholds for relationships between impacts of rationing of nursing care and nurse-and patient-reported outcomes in Swiss hospitals: a correlational study. International Journal of Nursing Studies, 46(7):884-893.

https://doi.org/10.1016/j.ijnurstu.2008.10.008

Schubert, M., Clarke, S. P., Aiken, L. H., \& de Geest, S. (2012). Associations between rationing of nursing care and inpatient mortality in Swiss hospitals. International Journal for Quality in Health Care, 24(3):230-238.

https://doi.org/10.1093/intqhc/mzs009

Schubert, M., Ausserhofer, D., Desmedt, M., Schwendimann, R., Lesaffree, E., Li, B., \& De Geest, S. (2013). Levels and correlates of implicit rationing of nursing care in Swiss acute care hospitals - a cross sectional study. International Journal of Nursing Studies, 50(2):230-239. https://doi.org/10.1016/j.ijnurstu.2012.09.016

Schwab, F., Meyer, E., Geffers, C., \& Gastmeier, P. (2012). Understaffing, overcrowding, inappropriate nurse: ventilated patient ratio and nosocomial infections: which parameter is the best reflection of deficits? Journal of Hospital Infection, 80(2):133-139. https://doi.org/10.1016/j.jhin.2011.11.014

Suetens, C., Hopkins, S., Kolman, J., \& Högberg, L. D. (2013, July 4). Point prevalence survey of healthcare-associated infections and antimicrobial use in European acute care hospitals 2011-2012. European Centre for Disease Prevention and Control.

https://www.ecdc.europa.eu/en/publications-data/pointprevalence-survey-healthcare-associated-infections-andantimicrobial-use-0

Tesoro, M., Peyser, D. J., \& Villarente, F. (2018). A retrospective study of non-ventilator-associated hospital acquired pneumonia incidence and missed opportunities for nursing care. The Journal of Nursing Administration, 48(5):285-291.

https://doi.org/10.1097/NNA.0000000000000614

The Research Committee of the Society of Healthcare Epidemiology of America. Enhancing patient safety by reducing healthcare-associated infections: the role of discovery and dissemination. (2010). Infection Control and Hospital Epidemiology, 31(2):118-123.

https://dx.doi.org/10.1086\%2F650198

Wakefield, B. J. (2014). Facing up to the reality of missed care. BMJ Quality \& Safety, 23(2):92-94.

https://doi.org/10.1136/bmjqs-2013-002489

Zeleníková, R., Gurková, E., \& Jarošová, D. (2019). Missed nursing care measured by MISSCARE Survey - the first pilot study in the Czech Republic and Slovakia. Central European Journal of Nursing and Midwifery, 10(1):958-966. http://dx.doi.org/10.15452/CEJNM.2019.10.0002 